\title{
Analytical Calculation of Magnetic Field Distribution and Stator Iron Losses for Surface-Mounted Permanent Magnet Synchronous Machines
}

\author{
Zhen Tian, Chengning Zhang * and Shuo Zhang \\ National Engineering Laboratory for Electric Vehicles, Beijing Institute of Technology, No. 5 South \\ Zhongguancun Street, Haidian District, Beijing 100081, China; tianzhen1118@hotmail.com (Z.T.); \\ 2120110462@bit.edu.cn (S.Z.) \\ * Correspondence: mrzhchn@bit.edu.cn; Tel.: +86-10-6891-2947 \\ Academic Editor: K.T. Chau
}

Received: 22 December 2016; Accepted: 28 February 2017; Published: 7 March 2017

\begin{abstract}
Permanent-magnet synchronous machines (PMSMs) are widely used in electric vehicles owing to many advantages, such as high power density, high efficiency, etc. Iron losses can account for a significant component of the total loss in permanent-magnet (PM) machines. Consequently, these losses should be carefully considered during the PMSM design. In this paper, an analytical calculation method has been proposed to predict the magnetic field distribution and stator iron losses in the surface-mounted permanent magnet (SPM) synchronous machines. The method introduces the notion of complex relative air-gap permeance to take into account the effect of slotting. The imaginary part of the relative air-gap permeance is neglected to simplify the calculation of the magnetic field distribution in the slotted air gap for the surface-mounted permanent-magnet (SPM) machine. Based on the armature reaction magnetic field analysis, the stator iron losses can be estimated by the modified Steinmetz equation. The stator iron losses under load conditions are calculated according to the varying $\mathrm{d}$-q-axis currents of different control methods. In order to verify the analysis method, finite element simulation results are compared with analytical calculations. The comparisons show good performance of the proposed analytical method.
\end{abstract}

Keywords: permanent magnet synchronous machine (PMSM); magnetic field distribution; iron losses; analytical calculation

\section{Introduction}

Nowadays, permanent-magnet synchronous machines (PMSM) are becoming a preferred choice for electric vehicle application, due to their high power density, high efficiency and high reliability [1-4]. Surface-mounted permanent magnet (SPM) machines are widely used because of their simple structure, which brings the advantages of easy manufacturing, maintenance, and recycling. The main problem with SPM machines is the existence of losses. Iron losses can account for a significant component of the total loss in PM machines [5-7]. Optimum design of PM machines therefore requires good means for predicting these iron losses [8].

During recent years, the problem of the stator iron losses in synchronous machines has been deeply analyzed [9-13]. However, most of them are partly or totally using finite-element method. Although accurate field calculations and losses can be carried out, numerical methods generally consume more time and do not provide closed-form solutions. Alternatively, an analytical calculation method can commonly be used to obtain solutions expressed in the form of a Fourier series which is flexible as a design tool for predicting the losses and motor performance [14]. 
Some analytical methods have been proposed to determine the magnetic field distribution of PM machines [15-19]. An exact field solution in the air gap of an SPM motor with radial or parallel magnetization was given in $[15,16]$. The method is based on a two-dimensional (2-D) analytical solution of the Laplacian and quasi-Poisonian equations with assumptions that the iron is infinitely permeable and the air gap is slotless. The effect of slotting was subsequently modeled in [17] by using relative air-gap permeance obtained from the results of conformal transformation of the slot geometry. The method presented in [14] provides a more complete analytical field solution than found in literature and allows one to accurately calculate both radial and tangential components of the air-gap flux density in the slotted air gap. It uses the complex nature of the conformal transformation more extensively and defines the relative air-gap permeance as a complex number.

In [18], the magnets on the rotor are segmented into magnet pieces of simple regular shape and uniform magnet property. The magnetic field of the machine is obtained by the superposition of the magnetic field due to each segment. In [19], an analytical modeling of the magnetic flux density distribution in the air gap is presented, based on the armature reaction magnetic field analysis of interior permanent magnet synchronous machine (IPMSM). In [20], a new armature reaction magnetic field model is proposed for the IPM motor, considering the effect of the embedded magnet in the rotor. Both iron loss and the magnetic flux density distribution under load conditions are predicted while the effect of slotting is ignored. In [21], an analytical model was developed to calculate the eddy current losses, in which the fictious voltage is used to evaluate the losses and the load current effects were taken into account, but the study was only qualitative.

In this paper, an analysis method is proposed to predict the magnetic field in the slotted air gap for the SPM machine. Based on the magnetic flux density distribution, the stator iron losses can be estimated by the modified Steinmetz equation under load condition according to the varying d-q-axis currents of different control methods. A simplification has been made in this paper which neglects the imaginary part of the relative air-gap permeance in the calculation. Both the stator iron losses and the magnetic flux density distribution calculated by the proposed analysis method are compared to the finite element method.

\section{Stator Iron Losses Calculation Principle of SPM Machines}

In the PMSMs, maximum torque per Ampere control (MTPA) and flux-weakening control are widely used when the PMSMs operate under constant torque and constant power modes in electric vehicles. The varying $\mathrm{d}$-q-axis currents produce different armature reaction magnetic fields. The magnitude and harmonic content of the magnetic field in the air gap are changing with the interaction between the armature reaction magnetic fields and the permanent magnetic field. This changing causes losses in the machines.

In this paper, an analytical calculation method is proposed to calculate the magnetic flux density and stator iron losses in the SPM machines. Figure 1 shows the procedure of the proposed method. The air gap flux density caused by armature reaction can be calculated when the d-q-axis currents under any specified load condition are obtained. The air gap flux density caused by permanent magnets can be calculated when the SPM is operating at a no-load state. Taking into account the effect of slotting, the complex relative air-gap permeance is introduced into the method. Then the stator tooth and yoke flux density are obtained based on the air gap flux density. Therefore, the stator iron losses can be calculated by the modified Steinmetz equation. 


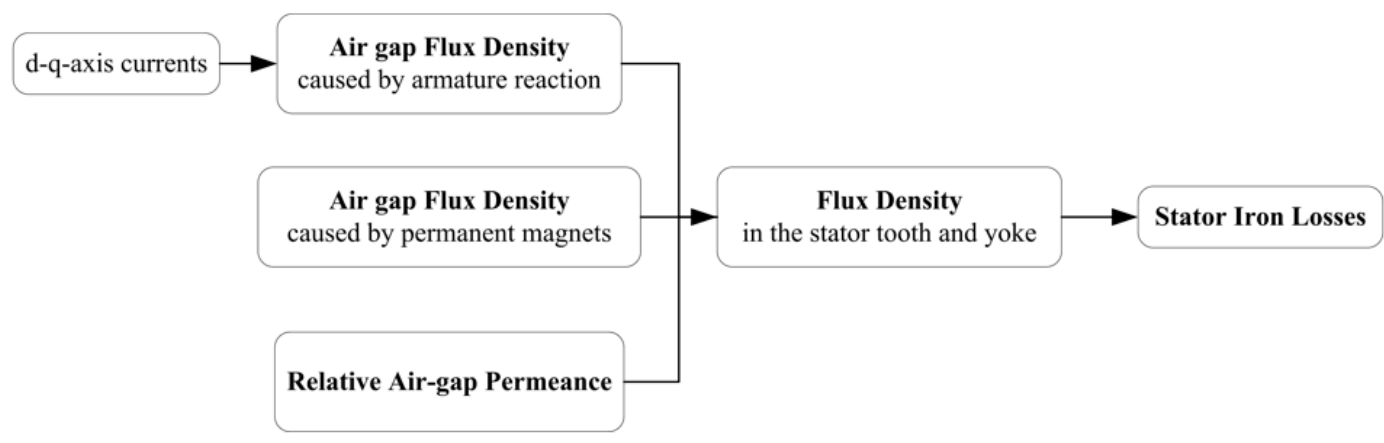

Figure 1. Stator iron losses calculation principle of SPM machines.

\section{Analytical Calculation Method}

\subsection{Air Gap Flux Density Caused by Armature Reaction}

For the sake of simplicity, it is assumed that: (1) the permeability of the core is infinite; (2) the influence of the winding end is ignored; (3) the permeability of the permanent magnet material is equal to the air.

The d-axis current $I_{d}$ and q-axis current $I_{q}$ under certain operating conditions can be calculated by the Flux Equation, Voltage Equation, and Electromagnetic Torque Equation, etc. according to the actual vector control method of the PMSM. $I_{d}, I_{q}$ and the input power $P_{\text {input }}$ [22] can be obtained as

$$
\left\{\begin{array}{l}
I_{d}=\frac{R_{1} U_{N} \sin \theta+X_{q}\left(E_{0}-U_{N} \cos \theta\right)}{X_{d} X_{q}+R_{1}^{2}} \\
I_{q}=\frac{X_{d} U_{N} \sin \theta-R_{1}\left(E_{0}-U_{N} \cos \theta\right)}{X_{d} X_{q}+R_{1}^{2}} \\
P_{\text {input }}=\frac{m}{X_{d} X_{q}+R_{1}^{2}} \times\left[E_{0} U_{N}\left(X_{q} \sin \theta-R_{1} \cos \theta\right)+R_{1} U_{N}^{2}+0.5 U_{N}^{2}\left(X_{d}-X_{q}\right) \sin 2 \theta\right]
\end{array}\right.
$$

where $\theta$ is the power angle, $R_{1}$ is the armature winding resistance, $U_{N}$ is the magnitude of converter output line voltage, $E_{0}$ is the back electromotive force without load at certain speed, and $X_{d}$ and $X_{q}$ are the $\mathrm{d}$-axis and $\mathrm{q}$-axis synchronous reactance, respectively, $m$ is the phase number.

When the PMSM operates at certain speed, a series of $I_{d}, I_{q}$ and $P_{\text {input }}$ corresponding to the power angle $\theta$ can be obtained after calculating the $R_{1}, E_{0}, X_{d}$, and $X_{q}$ at different power angle $\theta$ according to the load status. The internal power-factor angle $\psi$ and the maximum value of the phase current $I_{\Phi}$ are defined as

$$
\left\{\begin{array}{l}
\psi=\arctan \frac{I_{d}}{I_{q}} \\
I_{\Phi}=\sqrt{2} \cdot \sqrt{I_{d}^{2}+I_{q}^{2}}
\end{array}\right.
$$

Then the three-phase currents can be expressed as

$$
\left\{\begin{array}{l}
i_{a}=I_{\Phi} \cos (\omega t-\psi) \\
i_{b}=I_{\Phi} \cos \left(\omega t-\frac{2}{3} \pi-\psi\right) \\
i_{c}=I_{\Phi} \cos \left(\omega t-\frac{4}{3} \pi-\psi\right)
\end{array}\right.
$$

where $\psi$ is measured from the $\mathrm{d}$-axis, $\omega t$ is the instantaneous rotor angular position, and $I_{\Phi}$ is the maximum value of the current flowing through the phase.

For a single coil, the current $i_{a}$ above produces the magnetic flux density [23] as follows

$$
B(r, \alpha, t)=\cos (\omega t-\psi) \sum_{m=1}^{\infty} B_{\alpha m} \cos (m \alpha)
$$


where $\alpha$ is the angular variable, $r$ is the diameter in polar coordinates, $m$ is the harmonic order, and $B_{\alpha m}$ is the $m$ th order radial component of the air gap flux density which can be calculated by

$$
B_{\alpha m}=4 \frac{\mu_{0} R_{s} N_{s} I_{\phi} \mu}{\pi a b_{0} r} \frac{1}{m}\left(\frac{R_{s}}{r}\right)^{m}\left(\frac{r^{2 m}+R_{r}^{2 m}}{R_{s}^{2 m}-R_{r}^{2 m}}\right) \sin \left(m \frac{\alpha_{y}}{2}\right) \sin \left(m \frac{\alpha_{0}}{2}\right)
$$

where $\mu_{0}$ is the permeability of free space, $R_{s}$ is the inner diameter of the stator, $R_{r}$ is the outer diameter of the rotor, $N_{s}$ is the number of turns of the coil, $a$ is the number of the parallel branches, $b_{0}$ is the width of the slot, $\alpha_{y}$ is the span angle of the coil, and $\alpha_{0}$ is the notch width angle.

For double-stack coils, the radial component of armature reaction flux density for Phase A can be obtained by using the superposition principle as

$$
B_{a}(r, \alpha)=\sum_{n=1}^{q} \sum_{m=1}^{\infty} B_{a m} \cos \left[m p\left(\alpha-\frac{2 n-q-1}{2} \alpha_{t}\right)\right]
$$

where $q$ is the number of coils per pole in Phase A, $p$ is pole number, and $\alpha_{t}$ is the space angle of the adjacent two coils. For the double-layer winding, $\alpha_{t}=\alpha_{y}$.

When the three-phase currents given as (3) go into the three-phase winding, the armature reaction flux density of Phases B and C can be obtained in the same way. Therefore, the flux density of the resultant magnetic field in the air gap can be given as

$$
\begin{aligned}
B_{0}(r, \alpha, t) & =B_{a}(r, \alpha, t)+B_{b}(r, \alpha, t)+B_{c}(r, \alpha, t) \\
& =B_{a}(r, \alpha) \cos (\omega t)+B_{b}\left(r, \alpha-\frac{2 \pi}{3}\right) \cos \left(\omega t-\frac{2 \pi}{3}\right)+B_{c}\left(r, \alpha+\frac{2 \pi}{3}\right) \cos \left(\omega t+\frac{2 \pi}{3}\right)
\end{aligned} .
$$

\subsection{Relative Air-Gap Permeance}

The relative air-gap permeance is an important parameter to accurately analyze the magnetic field distribution of the machines. An internal rotor SPM machine with radial magnetization shown in Figure 2a is an example. The permeance of the slotted air gap/magnet region can be calculated by assuming no magnets present and infinitely deep rectilinear stator slots as shown in Figure $2 b$. The conformal transformations are suitable for the purpose of making the calculation simpler.

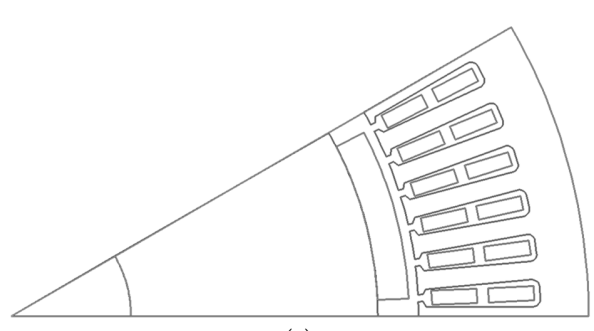

(a)

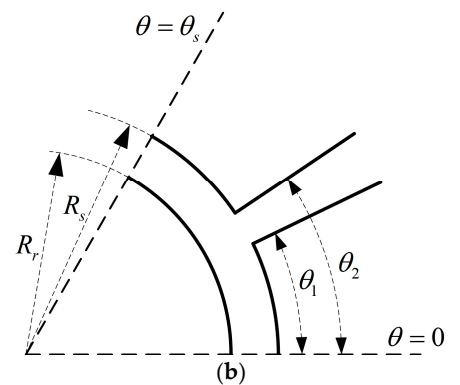

Figure 2. An internal rotor SPM machine example to explain the calculation of the relative air-gap permeance. (a) Cross section of one pole pitch of the SPM; (b) Infinite slot in the S plane.

There are four conformal transformations required to transform the slotted air gap into a slotless air gap. The original geometry shown in Figure $2 \mathrm{~b}$ represents a single slot opening in the $S$ plane. The transformation from $S, Z, W, T$ Plane to $K$ Plane $[14,17,24]$ is according to Formula (8)

$$
\left\{\begin{array}{l}
S \rightarrow Z: z=\ln (s)=\ln \left(r e^{j \theta}\right) \\
Z \rightarrow W: z=j \frac{g^{\prime}}{\pi}\left[\ln \left(\frac{1+q}{1-q}\right)-\ln \left(\frac{b+q}{b-q}\right)-\frac{b-1}{\sqrt{b}} \arctan \frac{q}{\sqrt{b}}\right]+c \\
W \rightarrow T: t=j \frac{g^{\prime}}{\pi} \ln (w)+\ln \left(R_{s}\right)+j \frac{\theta_{s}}{2} \\
T \rightarrow K: k=e^{t}
\end{array}\right.
$$


where

$$
\begin{aligned}
& q=\sqrt{\frac{w-b}{w-a}} \\
& a=1 / b \\
& b=\left[b_{0}^{\prime} / 2 g^{\prime}+\sqrt{\left(b_{0}^{\prime} / 2 g^{\prime}\right)^{2}+1}\right]^{2} . \\
& b_{0}^{\prime}=\theta_{2}-\theta_{1} \\
& g^{\prime}=\ln \left(R_{s} / R_{r}\right) \\
& c=\ln R_{s}+j \theta_{2}
\end{aligned}
$$

The relative air-gap permeance is a complex number and it can be written in the form

$$
\lambda=\lambda_{a}+j \lambda_{b}=\frac{\partial k}{\partial s}=\frac{\partial k}{\partial t} \frac{\partial t}{\partial w} \frac{\partial w}{\partial z} \frac{\partial z}{\partial s}=\frac{k}{s} \frac{w-1}{\sqrt{(w-a)(w-b)}}
$$

Since the tangential magnetic field is small relative to the radial magnetic field, only the real part $\lambda_{a}$ of the relative air-gap permeance is considered in the calculation.

\subsection{Air-Gap Flux Density Caused by Permanent Magnets}

Ignoring the magnetic saturation in the SPM machine, the air gap flux density caused by a permanent magnet [15] can be equivalent to the product of the air gap flux density generated by the PM in the smooth air gap and the relative air-gap permeance as stated in Formula (10).

Hence when $n p \neq 1$, the flux density of the smooth air gap in the polar coordinates is deduced as

$$
\begin{aligned}
B_{r}(r, \theta)= & \sum_{n=1,3 \ldots}^{\infty} \frac{\mu_{0} M_{n}}{\mu_{r}} \frac{n p}{(n p)^{2}-1}\left[\left(\frac{r}{R_{s}}\right)^{n p-1}\left(\frac{R_{m}}{R_{s}}\right)^{n p+1}+\left(\frac{R_{m}}{r}\right)^{n p+1}\right], \\
& \left\{\frac{(n p-1)+2\left(\frac{R_{r}}{R_{m}}\right)^{n p+1}-(n p+1)\left(\frac{R_{r}}{R_{m}}\right)^{2 n p}}{\frac{\mu_{r}+1}{\mu_{r}}\left[1-\left(\frac{R_{r}}{R_{s}}\right)^{2 n p}\right]-\frac{\mu_{r}-1}{\mu_{r}}\left[\left(\frac{R_{m}}{R_{s}}\right)^{2 n p}-\left(\frac{R_{r}}{R_{m}}\right)^{2 n p}\right]}\right\} \cos (n p \theta),
\end{aligned}
$$

where $\theta$ is the angular position with reference to the center of a magnet pole, $\mu_{r}$ is the relative recoil permeability, $R_{m}$ is the permanent magnet surface outer diameter, and $M_{n}$ is given by

$$
M_{n}=2\left(B_{r} / \mu_{0}\right) \alpha_{p}\left[\sin \left(n \alpha_{p} \pi / 2\right) /\left(n \alpha_{p} \pi / 2\right)\right],
$$

where $B_{r}$ is the remanence and $\alpha_{p}$ is the magnet pole-arc to pole-pitch ratio.

For the particular case when $n p=1$,

$$
B_{r}(r, \theta)=\frac{\mu_{0} M_{1}}{2 \mu_{r}}\left[1+\left(\frac{R_{s}}{r}\right)^{2}\right]\left\{\frac{1-\left(\frac{R_{r}}{R_{m}}\right)^{2}+\left(\frac{R_{r}}{R_{m}}\right)^{2} \ln \left(\frac{R_{m}}{R_{r}}\right)^{2}}{\frac{\mu_{r}+1}{\mu_{r}}\left[\left(\frac{R_{s}}{R_{m}}\right)^{2}-\left(\frac{R_{r}}{R_{m}}\right)^{2}\right]-\frac{\mu_{r}-1}{\mu_{r}}\left[1-\frac{\left(R_{s} R_{r}\right)^{2}}{R_{m}^{4}}\right]}\right\} \cos \theta,
$$

\subsection{On-Load Flux Density in Air Gap and Stator}

The on-load flux density in air gap is equal to

$$
B_{g}(r, \alpha, \gamma, t)=\left[B_{r}(r, \alpha-\gamma)+B_{0}(r, \alpha, t)\right] \cdot \lambda(r, \alpha),
$$

where $\gamma$ is the angular position in the stator reference frame measured from the Phase A axis.

In a pitch, the corresponding air gap flux is all through the stator teeth and yoke. So the flux density in the stator teeth can be deduced as (14), and the flux density in the stator yoke is derived as (15).

$$
\left\{\begin{array}{l}
B_{t}(\omega t)=\frac{\tau_{s}}{\alpha_{s} b_{t}} \int_{-\alpha_{s}}^{+\alpha_{s} / 2} B_{g}\left(\theta_{s}, \omega t\right) d \theta_{s} \\
B_{y}(\omega t)=\frac{\tau_{p}}{2 b_{y} \pi} \int_{-\frac{\pi}{2}}^{\frac{\pi}{2}} B_{g}(\theta, \omega t) d \theta
\end{array},\right.
$$


where $\alpha_{s}$ is one tooth pitch angle, $\tau_{s}$ is one tooth pitch, $b_{t}$ is the tooth width, $\tau_{p}$ is the pole pitch in air gap, and $b_{y}$ is the yoke height.

\subsection{Stator Iron Losses}

Considering that the flux density $B$ is caused by sinusoidal supply currents and magnets, the eddy-current excess loss in the stator can be ignored comparing with the hysteresis loss and eddy current loss. The stator teeth and yoke iron loss density can be decomposed into hysteresis loss component $p_{h}$ and eddy current loss component $p_{e}$, where the eddy current loss can be expressed in time domain form

$$
p=p_{h}+p_{e}=k_{h} f B_{\max }^{2}+\frac{1}{2 \pi^{2}} k_{e} \frac{1}{T} \int_{0}^{T}\left(\sum_{n=1,3,5, \ldots}^{\infty} \frac{\partial B(\omega t)}{\partial t}\right)^{2} d t,
$$

where $p_{h}$ is the hysteresis loss density, $p_{e}$ is the eddy loss density, $f$ is the fundamental frequency, $k_{h}$ is the hysteresis loss coefficient, and $k_{e}$ is the eddy current loss coefficient. The $k_{h}$ and $k_{e}$ should be obtained from a material data sheet.

According to the magnetic flux density from (14), the iron loss density of the stator tooth and the yoke can be calculated as follows

$$
\left\{\begin{array}{l}
p_{t}=k_{h} f B_{t_{-} \max }^{2}+\frac{1}{2 \pi^{2}} k_{e} \frac{1}{T} \int_{0}^{T}\left(\sum_{n=1,3,5, \ldots}^{\infty} \frac{\partial B_{n, t}(\omega t)}{\partial t}\right)^{2} d t \\
p_{y}=k_{h} f B_{y_{\_} \max }^{2}+\frac{1}{2 \pi^{2}} k_{e} \frac{1}{T} \int_{0}^{T}\left(\sum_{n=1,3,5, \ldots}^{\infty} \frac{\partial B_{n, y}(\omega t)}{\partial t}\right)^{2} d t
\end{array},\right.
$$

Moreover, the iron losses can be expressed as the product of the loss density and volume. The total stator iron losses can be given as

$$
P_{\text {total }}=V_{t} p_{t}+V_{y} p_{y}
$$

where $V_{t}$ is the stator teeth volume and $V_{y}$ is the stator yoke volume.

\section{Results and Discussions}

To validate the analytical calculation method in this paper, both the proposed model and the FEM are used to predict the magnetic flux density and iron losses under different speeds. The current excitation is the same sinusoidal current waveform when the PMSM operates at certain load conditions in both models.

\subsection{Motor Specification}

The electromagnetic performance of the SPM machines depends on many design parameters. The key design parameters are summarized as given in Table 1.

Table 1. SPM motor specification and design results.

\begin{tabular}{cccc}
\hline \multicolumn{2}{c}{ Specification } & \multicolumn{2}{c}{ Design Results (Parameters) } \\
\hline Rated power & $370 \mathrm{~kW}$ & Number of poles & 12 \\
Rated speed & $3185 \mathrm{rpm}$ & Number of slots & 72 \\
Rated torque & $1110 \mathrm{Nm}$ & Stator inner diameter & $340 \mathrm{~mm}$ \\
DC voltage & $900 \mathrm{~V}$ & Stator outer diameter & $482 \mathrm{~mm}$ \\
Maximum speed & $6000 \mathrm{rpm}$ & Stack length & $178 \mathrm{~mm}$ \\
Maximum output & $555 \mathrm{~kW}$ & Airgap length & $4 \mathrm{~mm}$ \\
Type of magnet & Sm-Co $(\mathrm{Br}=1.06 \mathrm{~T})$ & PM thickness & $13 \mathrm{~mm}$ \\
Steel sheet for core & B20AT1500 & Slot depth & $51 \mathrm{~mm}$ \\
\hline
\end{tabular}


For the SPM Machine, its operating characteristic curve and driving condition are shown in Figure 3. The rotational speed of the motor is varied from 0 to $6000 \mathrm{rpm}$. At low speed (0 to $3185 \mathrm{rpm}$ ), the motor is under the maximum torque per ampere control (MTPA). The MTPA control is under the current and voltage limits at rated speed for motor operation. The proposed control can also achieve the minimum current at certain torque demand and it also brings the objective of minimum copper loss. On the other hand, in case of high speed (3185 to $6000 \mathrm{rpm}$ ), the motor is controlled by the flux-weakening method. In this method, the line voltage is under the limitation determined by the DC voltage of the inverter. Meanwhile, the phase angle increases with the rotational speed in order to decrease the d-axis flux produced by the permanent magnet. Using the flux-weakening control, the high-speed range of the motor can be extended.

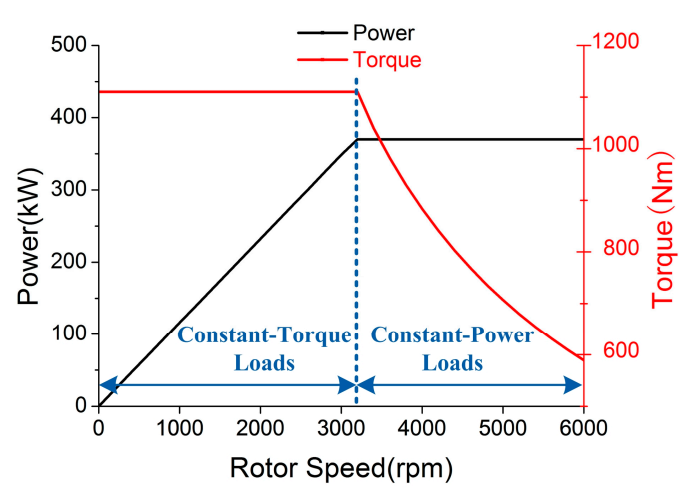

(a)

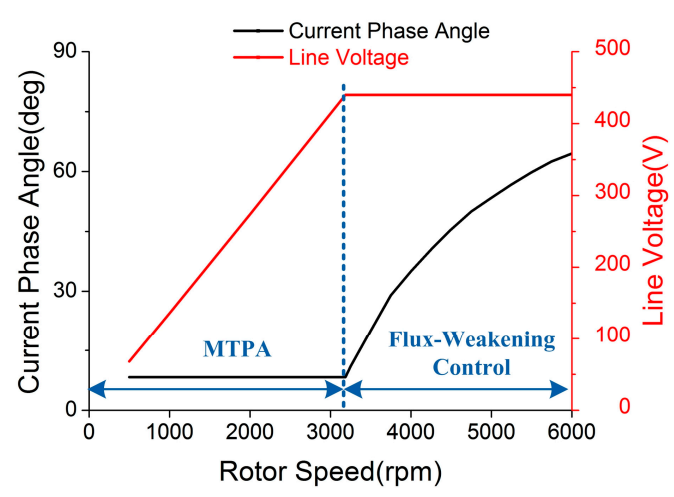

(b)

Figure 3. Operating characteristic curve and driving condition of the SPM Machine. (a) Operating characteristic curve of the SPM Machine; (b) Driving condition of the SPM Machine.

As the processes under different speeds are similar, the calculation and simulation of magnetic flux density at the rated point of $3185 \mathrm{rpm}$ with the same step size is presented as below.

\subsection{Relative Air-Gap Permeance and Flux Densities}

Before the calculation and simulation, the d-q-axis currents need to be given. In [21], the back electromotive force $E_{0}, \mathrm{~d}$-axis, and q-axis synchronous reactances $X_{d}$ and $X_{q}$, etc. can be obtained by the iterative calculation procedures while using the phasor diagram of PMSM with a certain control method. Then the armature currents $I_{d}$ and $I_{q}$ can be calculated from the Formulas (1) and (2). At the rated point of $3185 \mathrm{rpm}$, the armature currents are $I_{d}=75.1 \mathrm{~A}$ and $I_{q}=516.33 \mathrm{~A}$.

In the analytical calculation method, the complex relative air-gap permeance is introduced to consider the effect of slotting. Figure 4a represents the real component of the complex relative air-gap permeance calculated from Formulas (8)-(10) in the middle of the air gap in the SPM Machine. After being multiplied by the relative air-gap permeance, the air gap flux density is compared to the finite-element solution results.

All the air gap flux densities are calculated in the middle of the air gap. First, the air gap flux density caused by armature reaction at the rated operating point can be obtained from Formulas (3)-(7) as shown in Figure $4 \mathrm{~b}$. The air-gap flux density distribution waveforms have visible tooth ripples, while the up convex curve and down convex curve correspond to teeth and yokes, respectively. The errors between the analytical models and FE results are below $13.0 \%$ of FEM results, while $95.3 \%$ of the errors are below 10\%. The error between the proposed model and FEM is acceptable. 


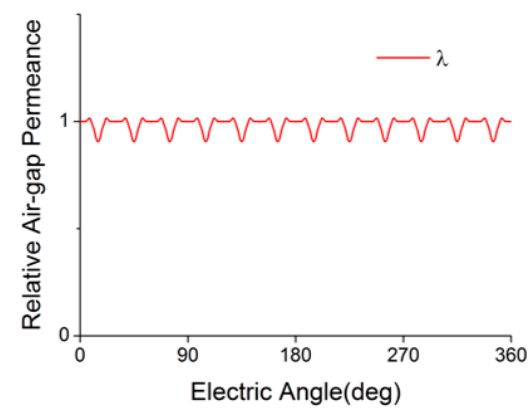

(a)

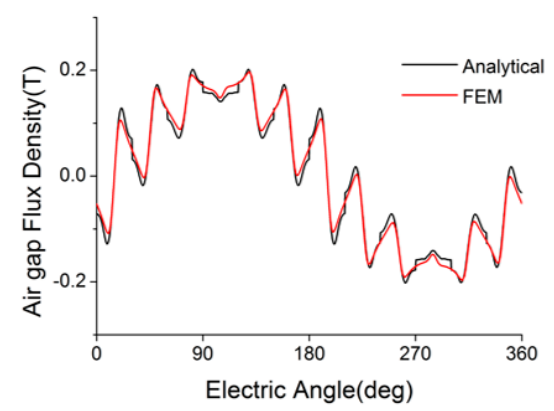

(b)

Figure 4. The complex relative air-gap permeance and the flux density in the middle of the air gap of the 12-pole SPM machine (a) Real component of the complex relative air-gap permeance; (b) Radial component of the flux density.

Secondly, the air gap flux density caused by permanent magnet is calculated from Formulas (11) and (12) as shown in Figure 5. The PMSM models with and without teeth both have been built to calculate the air gap flux density in the FE models. The errors between the analytical models and FE results are below $3.24 \%$ and $99.0 \%$ of the errors are below 3\% in Figure 5b. Obviously, the waveforms of the analytical calculation and finite element simulation agree well.

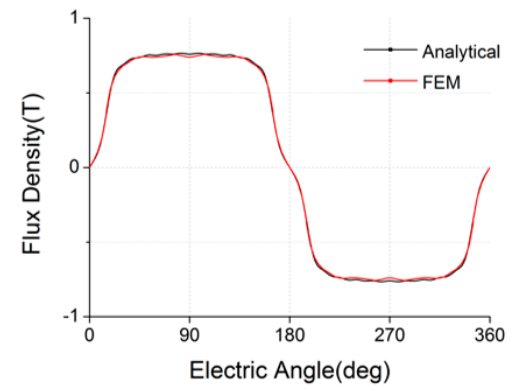

(a)

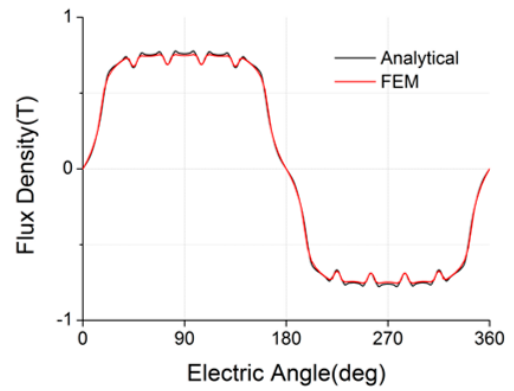

(b)

Figure 5. Air gap flux density caused by permanent magnet. (a) In the slotless air gap; (b) In the slotted air gap.

Figure 6 shows the air-gap flux density in the middle of the slotless air gap caused by permanent magnet, q-axis current and d-axis current, respectively. After summing them together, on-load air-gap flux density is shown in Figure 7a. 93.0\% of the errors between the analytical models and FE results are below $5 \%$ in Figure 7a. Meanwhile, the harmonic analysis results are shown in Figure $7 \mathrm{~b}$. The largest harmonics at this condition are 3rd, 11th, and 13rd. The comparisons to the FEM results show the good performance of the proposed analytical method.

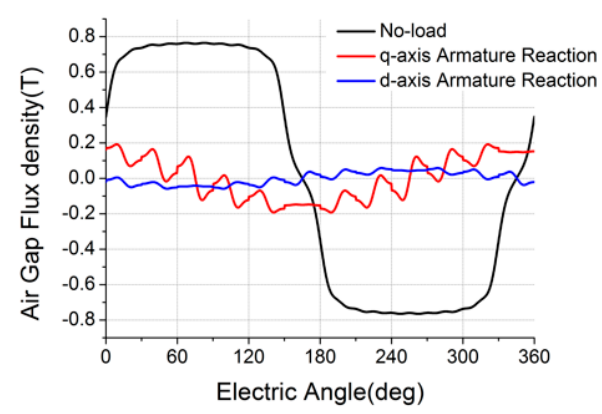

Figure 6. Air-gap flux density in the middle of the slotless air gap caused by permanent magnet, q-axis current and d-axis current respectively. 


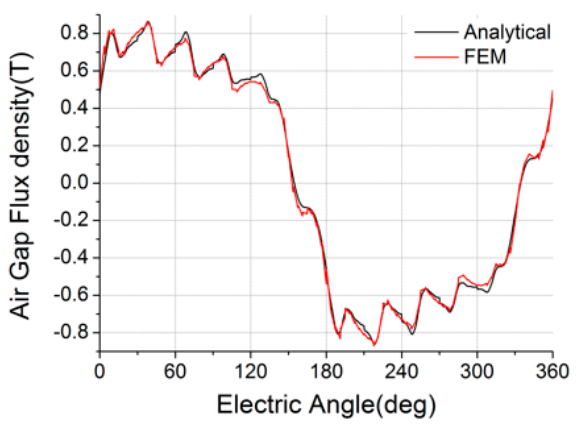

(a)

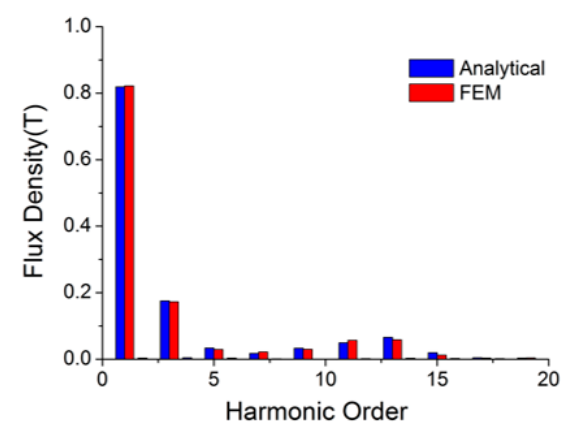

(b)

Figure 7. On-load air-gap flux density in the middle of the slotted air gap of the 12-pole SPM machine. (a) Waveform; (b) Spectrum.

The waveforms of $B_{t}$ and $B_{y}$ calculated according to Formula (15) are shown in Figure 8, where they are compared to the finite-element simulation results. Because of the pole-to-pole flux leakage, there is a little difference between the waveforms of the flux density calculated by analytical calculation and finite element method in the teeth. It is observed that the magnetic flux density in the teeth can be calculated more accurately in the SPM machines with fewer poles and more slots. As a result of ignoring the normal flux density, there is also a difference between the waveforms of the flux density calculated by analytical calculation and finite element method in the yoke. $86.2 \%$ of the errors in the teeth and $95.7 \%$ of the errors in the yokes between the analytical models and FE results are below $15 \%$. But basically, the agreement between the analytical calculation and FEM results is satisfactory. The results can be used in the stator iron losses calculation.

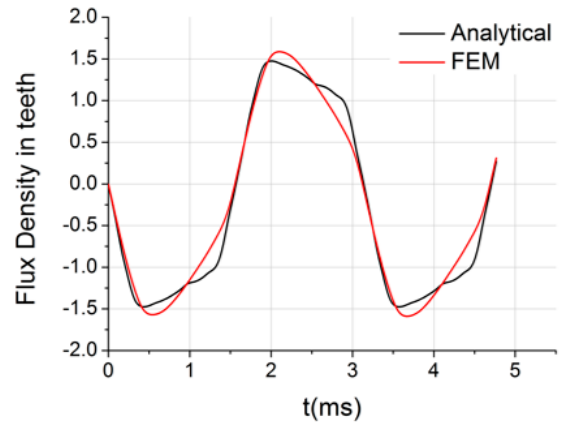

(a)

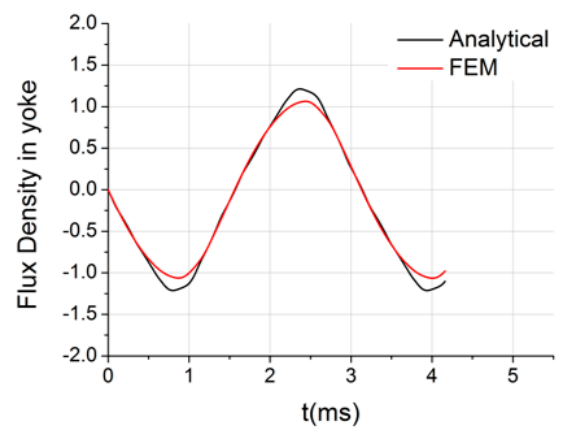

(b)

Figure 8. The magnetic flux density in the teeth and yoke under d-axis and q-axis current excitation. (a) Radial component of the flux density in stator teeth; (b) Tangential component of the flux density in stator yoke.

\subsection{Stator Iron Losses}

According to Formulas (17) and (18), the stator iron losses can be calculated. The current excitation is varied with different amplitude and phase. Figure 9a shows calculated stator iron losses due to the armature current and the rotational speed $(1000,2000,3185,4000,5000$, and $6000 \mathrm{rpm})$. Figure $9 \mathrm{~b}$ shows the ratio of the hysteresis losses and eddy current losses. Both the proposed analytical calculation and the finite element method are applied to estimate iron loss when the SPM machine operates at different rotational speeds. The iron losses obtained by the two methods are as shown in Figure 10. 


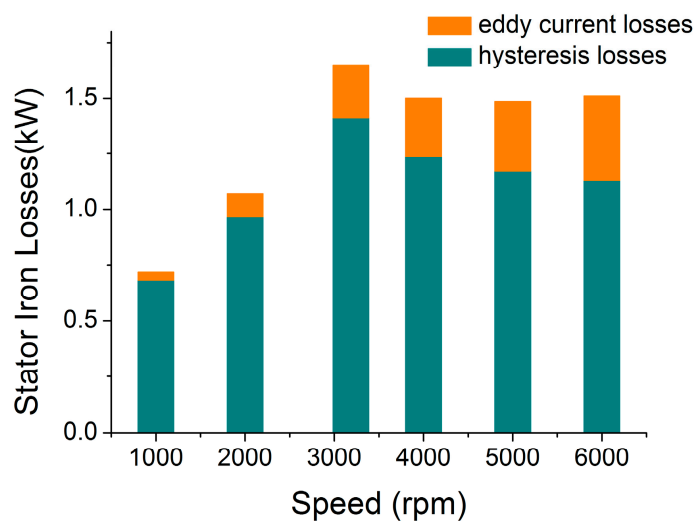

(a)

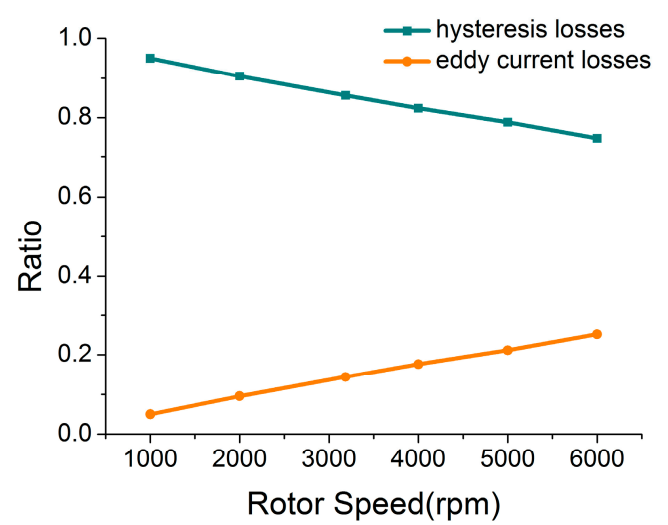

(b)

Figure 9. Calculated iron losses due to rotational speed. (a) Stator iron losses; (b) Ratio of the hysteresis losses and eddy current losses.

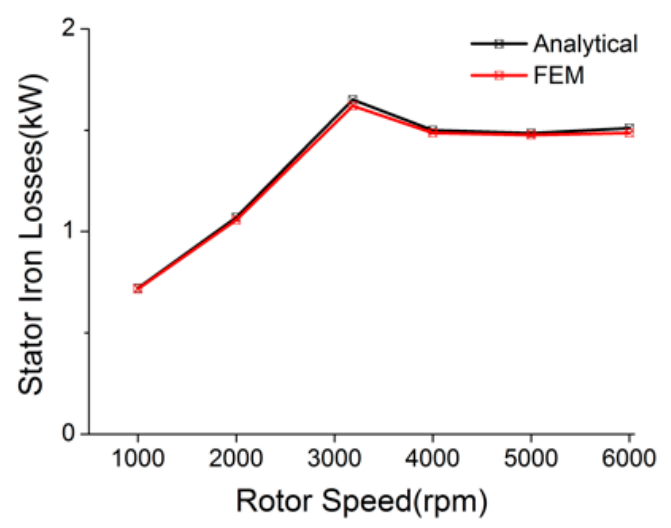

Figure 10. Stator iron losses of different rotational speeds (1000, 2000, 3185, 4000, 5000, and $6000 \mathrm{rpm})$.

In the low-speed region, the SPM machine is under the MPTA control. The fundamental frequency increases with the rotational speed while the flux densities change little. According to Formula (16), the stator iron losses increase with the speed. In the high-speed region, the fundamental frequency keeps increasing while the flux densities decrease with the d-q-axis current varying under the field-weakening control. This is the main reason for the stator iron loss changes as shown.

The results also indicate that the loss peaks when the SPM machine is working at the rated operating point. The difference of the two methods is acceptable, less than $3.0 \%$. Besides, the analytical calculation method was usually used to get the magnetic flux density and stator iron losses in the very beginning of the SPMSM design of electric vehicles, and it could save a lot of time during the SPMSM design optimization. The result of the proposed analytical calculation method agrees well with the FEM simulation result. The validity of the proposed analytical calculation method has been verified.

\section{Conclusions}

An improved analytical calculation method has been proposed to predict the magnetic field density distribution and the stator iron losses of the surface-mounted permanent magnet synchronous machines.

The approach is based on the armature reaction magnetic field for the SPMSM, which can predict a precise flux density distribution. Both magnetic flux density distribution and stator iron losses under sinusoidal current exciting are compared with the results of the FEM. In all studied for a wide operating speed range, the results of analytical calculations were in good agreement with the FEM results. 
Therefore, the proposed analytical method is very useful in predicting magnetic flux density distribution and stator iron losses for the SPMSMs, which makes this model a reliable tool for machine design and analysis, particularly for electric vehicles over a wide speed and load range.

Acknowledgments: This work was supported in part by the International Cooperation Research Program of China, Ref. 2015DFE72810.

Author Contributions: Zhen Tian conceived the proposed analytical calculation method of stator iron losses in the SPM machines, analyzed the data, and drafted the manuscript; Chengning Zhang contributed analysis tools; Shuo Zhang revised the full manuscript.

Conflicts of Interest: The authors declare no conflict of interest.

\section{References}

1. Yan, H.; Xu, Y.; Zou, J. A Phase Current Reconstruction Approach for Three-Phase Permanent-Magnet Synchronous Motor Drive. Energies 2016, 9, 853. [CrossRef]

2. Zhao, J.; Li, B.; Gu, Z. Research on an Axial Flux PMSM with Radially Sliding Permanent Magnets. Energies 2015, 8, 1663-1684. [CrossRef]

3. Liu, X.; Du, J.; Liang, D. Analysis and Speed Ripple Mitigation of a Space Vector Pulse Width Modulation-Based Permanent Magnet Synchronous Motor with a Particle Swarm Optimization Algorithm. Energies 2016, 9, 923. [CrossRef]

4. Chu, W.Q.; Zhu, Z.Q.; Chen, J.T. Simplified analytical optimization and comparison of torque densities between electrically excited and permanent-magnet machines. IEEE Trans. Ind. Electron. 2014, 61, 5000-5011. [CrossRef]

5. Atallah, K.; Zhu, Z.Q.; Howe, D. An improved method for predicting iron losses in brushless permanent magnet DC drives. IEEE Trans. Magn. 1992, 28, 2997-2999. [CrossRef]

6. Deng, F. An improved iron loss estimation for permanent magnet brushless machines. IEEE Trans. Energy Convers. 1999, 14, 1391-1395. [CrossRef]

7. Mi, C.; Slemon, G.R.; Bonert, R. Modeling of iron losses of permanent-magnet synchronous motors. IEEE Trans. Ind. Appl. 2003, 39, 734-742.

8. Bose, B.K. Power Electronics and Variable Frequency Drives. Technology and Applications; IEEE Press: Piscataway, NJ, USA, 1997.

9. Barcaro, M.; Bianchi, N. Air-gap flux density distortion and iron losses in anisotropic synchronous motors. IEEE Trans. Magn. 2010, 46, 121-126. [CrossRef]

10. Stumberger, B.; Hamler, A.; Hribernik, B. Analysis of iron loss in interior permanent magnet synchronous motor over a wide-speed range of constant output power operation. IEEE Trans. Magn. 2000, 36, 1846-1849. [CrossRef]

11. Tang, C.; Soong, W.L.; Liew, G.S.; Ertugrul, N.; Jahns, T.M. Analysis of stator iron loss in interior PM machines under open and short-circuit conditions. In Proceedings of the 2013 IEEE Energy Conversion Congress and Exposition, Denver, CO, USA, 15-19 September 2013; pp. 1227-1234.

12. Tangudu, J.K.; Jahns, T.M.; Ayman, E.R. Core loss prediction using magnetic circuit model for fractional-slot concentrated-winding interior permanent magnet machines. In Proceedings of the 2010 IEEE Energy Conversion Congress and Exposition, Atlanta, GA, USA, 12-16 September 2010; pp. 1004-1011.

13. Mi, C.; Slemon, G.R.; Bonert, R. Minimization of iron losses of permanent magnet synchronous machines. IEEE Trans. Energy Convers. 2005, 20, 121-127. [CrossRef]

14. Zarko, D.; Ban, D.; Lipo, T.A. Analytical calculation of magnetic field distribution in the slotted air gap of a surface permanent-magnet motor using complex relative air-gap permeance. IEEE Trans. Magn. 2006, 42, 1828-1837. [CrossRef]

15. Zhu, Z.Q.; Howe, D.; Bolte, E.; Ackermann, B. Instantaneous magnetic field distribution in brushless permanent magnet DC motors. I. Open-circuit field. IEEE Trans. Magn. 1993, 29, 124-135. [CrossRef]

16. Zhu, Z.Q.; Howe, D.; Chan, C.C. Improved analytical model for predicting the magnetic field distribution in brushless permanent-magnet machines. IEEE Trans. Magn. 2002, 38, 229-238. [CrossRef]

17. Zhu, Z.Q.; Howe, D. Instantaneous magnetic field distribution in brushless permanent magnet DC motors. III. Effect of stator slotting. IEEE Trans. Magn. 1993, 29, 143-151. [CrossRef] 
18. Wu, L.; Zhu, Z.Q. Analytical modeling of surface-mounted PM machines accounting for magnet shaping and varied magnet property distribution. IEEE Trans. Magn. 2014, 50, 1-11. [CrossRef]

19. Li, Q.; Fan, T.; Wen, X. An Improved Model of Estimating Iron Loss for Interior Permanent Magnet Synchronous Machine. In Proceedings of the 2013 IEEE Vehicle Power and Propulsion Conference (VPPC), Beijing, China, 15-18 October 2013; pp. 1-5.

20. Li, Q.; Fan, T.; Wen, X. Armature-reaction magnetic field analysis for interior permanent magnet motor based on winding function theory. IEEE Trans. Magn. 2013, 49, 1193-1201. [CrossRef]

21. Rabinovici, R.; Miller, T.J.E. Eddy-current losses of surface-mounted permanent-magnet motors. IEE Proc.-Electr. Power Appl. 1997, 144, 61-64. [CrossRef]

22. Tang, R.Y. Modern Permanent Magnet Machines: Theory and Design; China Machine Press: Beijing, China, 1997; pp. 161-215. (In Chinese)

23. Wang, X. Permanent Magnet Machine; China Electric Power Press: Beijing, China, 2011. (In Chinese)

24. Lin, F.; Zuo, S.; Ma, C.; Tan, Q. Analytical Calculation of Armature Reaction Field Including Slotting Effects in PMSM with Concentrated Fractional-Slot Winding. Trans. China Electrotech. Soc. 2014, 29, 29-35. (In Chinese)

(c) 2017 by the authors. Licensee MDPI, Basel, Switzerland. This article is an open access article distributed under the terms and conditions of the Creative Commons Attribution (CC BY) license (http:/ / creativecommons.org/licenses/by/4.0/). 